\title{
Effect of GnRH analogues on apoptosis and release of interleukin-1 $\beta$ and vascular endothelial growth factor in endometrial cell cultures from patients with endometriosis
}

\author{
Gabriela F.Meresman $^{1,3}$, Mariela A.Bilotas ${ }^{1}$, Eduardo Lombardi ${ }^{2}$, Marta Tesone ${ }^{1}$, \\ Carlos Sueldo $^{2}$ and Rosa I.Barañao \\ ${ }^{1}$ Instituto de Biología y Medicina Experimental (IBYME-CONICET), Vuelta de Obligado 2490, (C1428DNA) and ${ }^{2}$ Instituto de \\ Ginecología y Fertilidad (IFER), M.T. de Alvear 2259, (C1122AAI) Buenos Aires, Argentina
}

${ }^{3}$ To whom correspondence should be addressed. E-mail: meresman@dna.uba.ar

BACKGROUND: The aim of the present study was to evaluate the effect of GnRH analogues on the in-vitro eutopic endometrial cell apoptosis and release of interleukin-1 $\beta$ (IL-1 $\beta$ ) and vascular endothelial growth factor (VEGF). METHODS: Biopsy specimens of eutopic endometrium obtained from 16 women with untreated endometriosis and 14 controls were studied. Apoptosis, IL-1 $\beta$ and VEGF release were evaluated in epithelial endometrial cell cultures after incubation with leuprolide acetate (LA) as GnRH agonist, antide as GnRH antagonist, and a combination of both. The percentage of apoptotic cells was evaluated by the acridine orange-ethidium bromide technique, and IL-1 $\beta$ and VEGF concentrations were assessed by using commercial enzyme-linked immunosorbent assay (ELISA) kits. RESULTS: We found that LA $(100 \mathrm{ng} / \mathrm{ml})$ enhanced apoptosis in endometrial cell cultures from endometriosis patients and controls and this effect was reversed by antide at $10^{-7} \mathrm{~mol} / \mathrm{l}$. IL-1 $\beta$ and VEGF release was down-regulated by LA in cultures from controls and endometriosis patients. The addition of antide $10^{-7} \mathrm{~mol} / \mathrm{l}$ reversed this inhibition. Endometrial cultures treated with antide at $10^{-7} \mathrm{~mol} / \mathrm{l}$ did not show any significant effects compared with basal conditions. CONCLUSIONS: GnRH agonists appear to have a direct effect in endometrial cells cultures, by enhancing the percentage of apoptotic cells and decreasing the release of pro-mitogenic cytokines such as IL-1 $\beta$ and VEGF.

Key words: apoptosis/endometrial cell/endometriosis/GnRH agonist/IL-1 $\beta / \mathrm{VEGF}$

\section{Introduction}

Endometriosis is one of the most common benign disorders of the female pelvis during the reproductive years. It is now generally accepted that the pathogenesis of peritoneal endometriosis involves the implantation of exfoliated endometrium. Essential for its survival is the generation and maintenance of an extensive blood supply, both within and surrounding the ectopic tissue (McLaren, 2000). Accordingly, a number of studies have shown that for its survival, established ectopic tissue is dependent upon the peritoneal environment that supports angiogenesis (McLaren, 2000; Smith, 2001).

The vascular endothelial growth factor (VEGF) family of angiogenic molecules is involved in both physiological angiogenesis and a number of pathological conditions that are characterized by excessive angiogenesis (Liu et al., 2000; Bachelder et al., 2001; Harris et al., 2002). Increasing evidence suggests that VEGF may also be involved in the aetiology and maintenance of endometriosis (Donnez et al., 1998; McLaren, 2000; Smith, 2001).

VEGF is a highly specific mitogen for vascular endothelial cells (Neufeld et al., 1999). Several reports have demonstrated that VEGF not only induces angiogenesis, but also works as a survival factor for tumour and endothelial cells, protecting them from apoptosis (Liu et al., 2000; Harmey and BouchierHayes, 2002). We recently reported on the increased survival capability of the eutopic endometrium from patients with endometriosis, possibly regulated by an elevated expression of $\mathrm{Bcl}-2$, as well as on the impact of short-term oral contraceptives in reversing this effect (Meresman et al., 2000, 2002).

An immunological basis, mediated through various factors, has long been considered to be important in the pathogenesis of endometriosis (Sidell et al., 2002). Interleukin-1 $\beta$ (IL-1 $\beta$ ) is a pleiotrophic cytokine involved in the inflammatory immune response (Dinarello, 1997) and is known to act as a growth factor. In addition to its mitogenic effects, IL-1 $\beta$ induces the protection of different cells from apoptotic death (Markstrom et al., 2002; Simonart et al., 2002).

Both, IL-1 $\beta$ and VEGF are produced by endometrial cells and are critical factors involved in the pathogenesis of endometriosis (Donnez et al., 1998; Lebovic et al., 2000). Inflammatory cytokines, such as IL-1 $\beta$ and IL-6, were found to be elevated in the peritoneal fluid of women with endometriosis 
(Ho et al., 1997). In endometriotic cells, as in other tissues, the expression of VEGF was found to be potentiated by a variety of cytokines, especially IL-1 $\beta$ (Lebovic et al., 2000; Jung et al., 2001; Dias et al., 2002).

Among the most widely used hormonal treatments for endometriosis are the GnRH analogues (Rice et al., 2002). Leuprolide acetate (LA) is a GnRH agonist commonly prescribed for the treatment of endometriosis that acts primarily on the anterior pituitary, inducing initially an undesirable transient rise in gonadotrophin release. With continued administration, LA causes pituitary desensitization, leading to a complete suppression of gonadal function (Plosker et al., 1994). In addition, there is growing evidence supporting a direct action of GnRH agonists on endometrial growth, since both GnRH and $\mathrm{GnRH}$ receptors have been isolated from eutopic and ectopic endometrium (Borroni et al., 2000). It was suggested that GnRH may act as a direct regulator of this growth.

We recently showed that $\mathrm{GnRH}$ agonists have a beneficial effect on endometriosis, by diminishing cell proliferation and enhancing apoptosis in eutopic endometrium (Meresman et al., 2003). Nevertheless, the effect of GnRH agonists on the release of regulatory cytokines and angiogenic factors by the eutopic endometrium from patients with endometriosis, as well as the direct effect of $\mathrm{GnRH}$ antagonists on the same tissue, is as yet unknown.

Based on these data, the objectives of this work are (i) to study and compare the direct effect of a GnRH agonist and a GnRH antagonist on apoptosis in epithelial cells from eutopic endometrium obtained from endometriosis and control patients; and (ii) to evaluate the effect of a GnRH agonist and antagonist on the release of IL-1 $\beta$ and VEGF by the same endometrial cells in culture.

\section{Materials and methods}

\section{Patients}

A total of 30 infertile patients undergoing a diagnostic laparoscopy participated in the study: 16 patients were found to have endometriosis (stages I and II), while 14 patients without the disease served as controls. Staging of endometriosis was performed according to the American Society for Reproductive Medicine (1997). Control subjects were infertile women without endometriosis, with either tubal factor infertility or unexplained infertility, undergoing a diagnostic laparoscopy. All patients in the study had regular menstrual cycles and had not received any hormonal therapy during the previous 6 months. Biopsy specimens of eutopic endometrium were obtained from all subjects during the proliferative phase, as previously described (Meresman et al., 2000).

This study was approved by the Ethics and Research Committee of the Biology and Experimental Medicine Institute, and all subjects included in the study signed informed consent.

\section{Epithelial endometrial cell culture}

The tissue was immediately placed into culture medium and processed within $60 \mathrm{~min}$ of collection. Epithelial cells were enzymatically separated, isolated by successive centrifugation, and primary cultures established for in-vitro studies on implantation using a modification of the method described by Bongso et al. (1988).
Briefly, the explant was minced, washed and placed in basic medium (MEM D-Val, Gibco, Paisley, UK) containing $100 \mathrm{IU} / \mathrm{ml}$ penicillin, $100 \mu \mathrm{g} / \mathrm{ml}$ streptomycin and $25 \mu \mathrm{g} / \mathrm{ml}$ amphotericin B (Gibco) with $1 \mathrm{mg} / \mathrm{ml}$ collagenase (Gibco, type I). After a $2 \mathrm{~h}$ incubation at $37^{\circ} \mathrm{C}$ in an atmosphere of $5 \% \mathrm{CO}_{2}$, the resulting suspension was centrifuged at $100 \mathrm{~g}$ for $5 \mathrm{~min}$. The pellet containing glands was resuspended in nutrient medium and spun again at $100 \mathrm{~g}$ for $5 \mathrm{~min}$. The final pellet mainly contained epithelial cells. After a $1 \mathrm{~h}$ incubation, the medium containing enriched epithelial cells was removed and plated in fresh medium. The cells were cultured in quadruplicate for each patient, with $10 \%$ fetal bovine serum (FBS; Gibco) before the experiments.

Immunocytochemical evaluation for cytokeratin was done as described in our previous study, and the cells were identified as epithelial based on their intense labelling (Meresman et al., 2003).

\section{Apoptosis assay}

Cultures of epithelial cells were plated in 4-well culture dishes (Nalge Nunc International, NY) and left undisturbed at $37^{\circ} \mathrm{C}$ for 2 days. Prior to the addition of the different agents, the medium was changed to a low serum medium (MEM D-Val supplemented with 2.5\% FBS). Cultures were treated with LA (Lupron; Abbot, Buenos Aires, Argentina) $100 \mathrm{ng} / \mathrm{ml}$, as GnRH agonist, antide (ANT) (Sigma, St Louis, MO) at a concentration of $10^{-7} \mathrm{~mol} / \mathrm{l}$, as $\mathrm{GnRH}$ antagonist, or a combination of ANT and LA, adding LA $100 \mathrm{ng} / \mathrm{ml} 3 \mathrm{~h}$ after the supplementation with ANT $10^{-7} \mathrm{~mol} / \mathrm{l}(\mathrm{ANT}+\mathrm{LA})$. For each patient, one culture with four experimental treatments (basal, LA $100 \mathrm{ng} / \mathrm{ml}$, ANT $10^{-7} \mathrm{~mol} / \mathrm{l}$ and LA + ANT) were assessed in quadruplicate.

The percentage of apoptotic cells was assessed by the acridine orange-ethidium bromide technique in endometrial cultures, under basal conditions and after exposure to the different agents $(\mathrm{GnRH}$ agonist, GnRH antagonist or both).

Acridine orange is a vital dye that is excluded from viable cells. It is specific for apoptotic forms of cell death and does not significantly label cells undergoing necrotic death caused by injury (Abrams et al., 1993). After addition of the acridine orange (1 mg/l)-ethidium bromide $(250 \mathrm{mg} / \mathrm{l}) \mathrm{mix}$, the cells were viewed by a fluorescence microscope and the apoptotic cells were counted manually as a percentage of the total number of cells by two independent observers. Each observer viewed 30 randomly selected fields in a blind manner. There was no significant difference in results between the two observers $(P=0.63)$.

\section{Quantification of IL-1 $\beta$ and VEGF}

Epithelial cells cultures were left undisturbed at $37^{\circ} \mathrm{C}$ for 2 days. Subsequently, the cells were washed and incubated with basic medium supplemented with $2.5 \%$ FBS for an additional $48 \mathrm{~h}$ under basal conditions, after the addition of LA at $100 \mathrm{ng} / \mathrm{ml}$, ANT at $10^{-7} \mathrm{~mol} / \mathrm{l}$ and ANT $10^{-7} \mathrm{~mol} / \mathrm{l}+\mathrm{LA} 100 \mathrm{ng} / \mathrm{ml}$. The conditioned medium was collected and assayed for IL-1 $1 \beta$ and VEGF using commercial enzymelinked immunoassay (ELISA) kits (Cytimmune Sciences Inc., MD, USA). The sensitivity level for the IL- $1 \beta$ ELISA was $0.87 \mathrm{pg} / \mathrm{ml}$ and for the VEGF ELISA was $18.6 \mathrm{pg} / \mathrm{ml}$.

The intra-assay variability for IL-1 $\beta$ and VEGF was \pm 7.9 and $8.9 \%$ respectively, while the inter-assay variability was \pm 11.4 and $11.1 \%$ for IL-1 $\beta$ and VEGF respectively. All samples were assessed in triplicate.

\section{Statistics}

Statistical comparisons were performed by Kruskal-Wallis nonparametric ANOVA test, followed by Dunn's multiple comparison test. Regardless of the statistical test, only a $P$-value $\leqslant 0.05$ was considered significant. 


\section{Results}

\section{Effects of GnRH agonist and antagonist on epithelial endometrial cell apoptosis}

Exposure to LA significantly increased the level of apoptosis in cultures from patients and controls. LA at $100 \mathrm{ng} / \mathrm{ml}$ showed an effect on endometrial growth, enhancing apoptosis in endometrial cell cultures from patients with endometriosis from
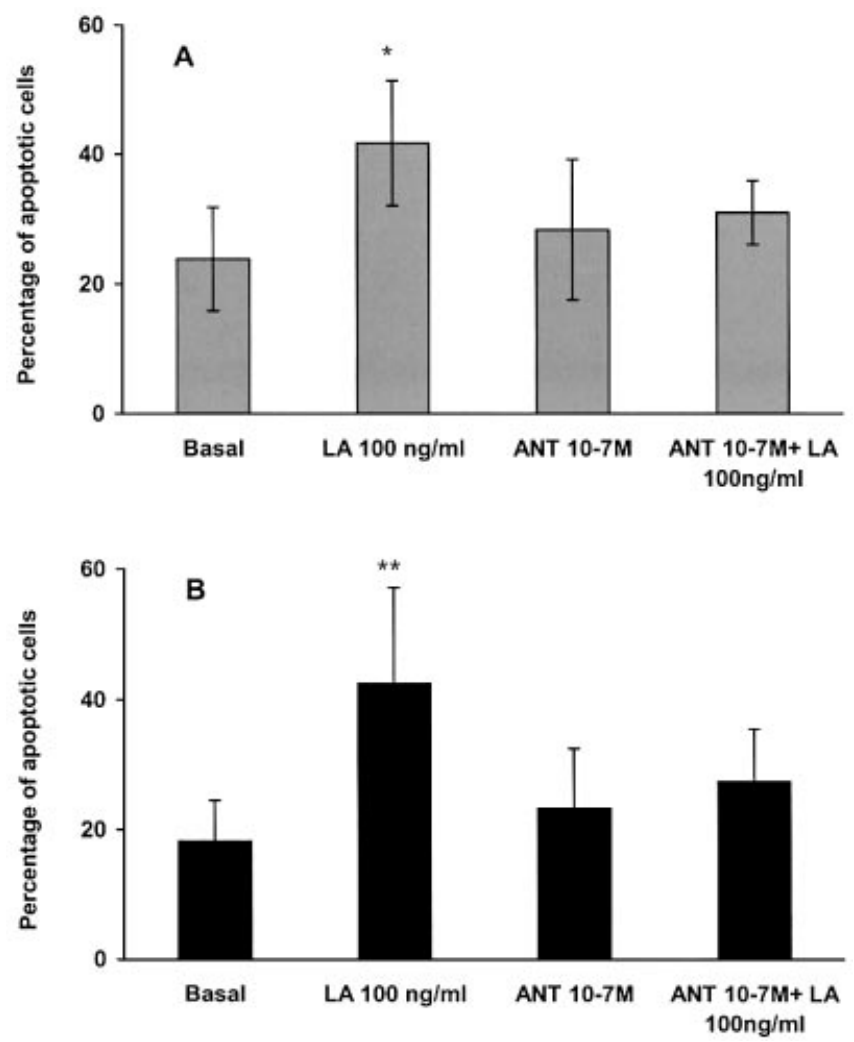

Figure 1. Effects of LA and ANT on apoptosis in endometrial cell cultures from subjects with (A) and without endometriosis (B). Epithelial cell cultures from patients with endometriosis and control subjects were analysed for apoptosis by the acridine orangeethidium bromide technique under basal conditions and stimulated with LA $100 \mathrm{ng} / \mathrm{ml}$ or ANT at a concentration of $10^{-7} \mathrm{M}$, or a combination of ANT and LA. Values are expressed as a percentage of apoptotic cells. The cells were viewed by a fluorescence microscope and apoptotic cells are expressed as a percentage of the total (see text). $* P<0.01$ versus basal; $* * P<0.05$ versus basal; ANT $10^{-7} \mathrm{~mol} / \mathrm{l}$ and ANT $10^{-7} \mathrm{~mol} / \mathrm{l}+\mathrm{LA} 100 \mathrm{ng} / \mathrm{ml}$ versus basal, $P>0.05$, NS.
$23.9 \pm 8.0$ to $41.7 \pm 9.6 \%$ (expressed as a percentage of apoptotic cells, mean $\pm \mathrm{SD}, P<0.01$ ) (Figure 1A), and from $18.2 \pm 6.3$ to $42.5 \pm 14.7 \%$ in cultures from controls $(P<0.05)$ (Figure 1B). In both experiments, this effect was prevented by adding ANT at $10^{-7} \mathrm{~mol} / \mathrm{l}$ ( $3 \mathrm{~h}$ prior to adding LA): in endometriosis $31.0 \pm 4.9 \%$, and in controls $27.3 \pm 8.1 \%$ (versus basal, $P>0.05$, NS) (Figure 1A and B). ANT by itself, at $10^{-7} \mathrm{~mol} / \mathrm{l}$, had no visible effect on basal apoptosis (Table I).

\section{Effects of GnRH agonist and antagonist on $I L-1 \beta$ release by epithelial endometrial cell cultures}

Exposure to LA significantly decreased the levels of IL-1 $\beta$, from $223.0 \pm 56.0$ to $83.6 \pm 16.3 \mathrm{pg} / \mathrm{ml}(P<0.05)$, and from $201.5 \pm 58.6$ to $96.1 \pm 54.8 \mathrm{pg} / \mathrm{ml}(P<0.03)$, in conditioned media from endometrial cell cultures in endometriosis patients and controls respectively (Figure 2).

This effect was prevented by adding ANT at $10^{-7} \mathrm{~mol} / \mathrm{l}(3 \mathrm{~h}$ prior to LA): in endometriosis patients $124.0 \pm 32.3 \mathrm{pg} / \mathrm{ml}$, and in controls $177.6 \pm 64.1 \mathrm{pg} / \mathrm{ml}$ (versus basal, $P>0.05$, NS) (Table I).

Endometrial cell cultures from endometriosis patients and controls treated with ANT at $10^{-7} \mathrm{~mol} / \mathrm{l}$ by itself did not show any significant difference compared with the levels of IL-1 $\beta$ found under basal conditions (Table I).

It is of interest that there was no difference in the release of IL-1 $\beta$ between the endometrial cell cultures from endometriosis and control patients.

\section{Effects of GnRH agonist and antagonist on VEGF release by epithelial endometrial cell cultures}

Exposure to LA significantly decreased the levels of VEGF from $283.6 \pm 83.9$ to $134.5 \pm 37.3 \mathrm{pg} / \mathrm{ml}(P<0.04)$, and from $250.9 \pm 60.8$ to $96.0 \pm 11.0 \mathrm{pg} / \mathrm{ml}(P<0.03)$, in conditioned media from endometrial cell cultures in endometriosis patients and controls respectively (Figure 3 ).

This effect was prevented by adding ANT at $10^{-7} \mathrm{~mol} / \mathrm{l}(3 \mathrm{~h}$ prior to LA): in endometriosis, $215.8 \pm 102.4 \mathrm{pg} / \mathrm{ml}$, and in controls $317.5 \pm 90.5 \mathrm{pg} / \mathrm{ml}$ (versus basal, $P>0.05$, NS) (Table I).

Endometrial cell cultures from endometriosis patients and controls treated with ANT at $10^{-7} \mathrm{~mol} / \mathrm{l}$ alone, did not show any significant difference in the levels of VEGF compared with basal conditions.

Table I. Apoptosis, IL-1 $\beta$ and VEGF release in epithelial endometrial cultures (EEC) from endometriosis patients and controls. Values are mean \pm SD.

\begin{tabular}{|c|c|c|c|c|c|c|}
\hline & \multicolumn{3}{|c|}{ EEC from endometriosis patients } & \multicolumn{3}{|c|}{ EEC from controls } \\
\hline & $\mathrm{ApC}(\%)$ & $\mathrm{IL}-1 \beta(\mathrm{pg} / \mathrm{ml})$ & VEGF (pg/ml) & $\mathrm{ApC}(\%)$ & $\mathrm{IL}-1 \beta(\mathrm{pg} / \mathrm{ml})$ & VEGF (pg/ml) \\
\hline Basal & $23.9 \pm 8.1^{+}$ & $223.0 \pm 56.0^{*}$ & $283.6 \pm 83.9 * *$ & $18.2 \pm 6.3^{*}$ & $201.5 \pm 58.6^{++}$ & $250.9 \pm 60.8^{++}$ \\
\hline LA & $41.7 \pm 9.7^{+}$ & $83.6 \pm 16.3^{*}$ & $134.5 \pm 37.3^{* *}$ & $42.5 \pm 14.7 *$ & $96.1 \pm 54.8^{++}$ & $96.0 \pm 11.0^{++}$ \\
\hline ANT & $28.4 \pm 10.8$ & $175.6 \pm 56.2$ & $248.8 \pm 76.9$ & $23.4 \pm 9.1$ & $116.6 \pm 17.4$ & $302.5 \pm 160.2$ \\
\hline $\mathrm{LA}+\mathrm{ANT}$ & $31.0 \pm 4.9$ & $124.0 \pm 32.3$ & $215.8 \pm 102.4$ & $27.4 \pm 8.1$ & $177.6 \pm 64.1$ & $317.5 \pm 90.5$ \\
\hline
\end{tabular}

The percentage of apoptotic cells (ApC) was estimated by the acridine orange-ethidium bromide technique under basal conditions and stimulated with

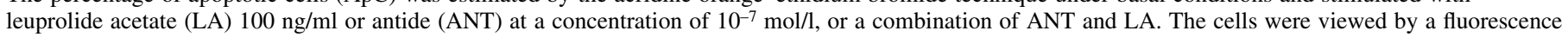
microscope and apoptotic cells are expressed as a percentage of the total.

The unstimulated (basal) and stimulated conditioned media from EEC were collected and assayed for IL-1 $\beta$ and VEGF using commercial ELISA kits. ${ }^{+} P<0.01,{ }^{++} P<0.03,{ }^{* *} P<0.04$ and $* P<0.05$ basal versus LA. 


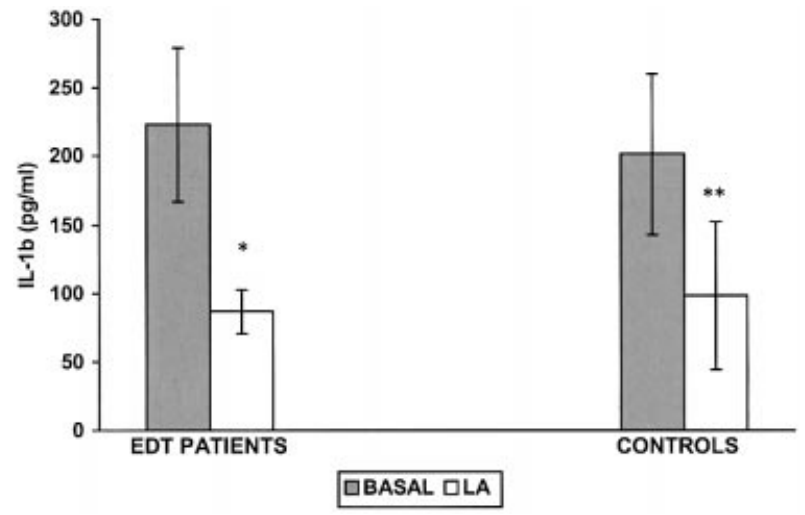

Figure 2. Effects of LA on IL-1 $\beta$ release by epithelial endometrial cell cultures. Epithelial cell cultures from patients with endometriosis (EDT) and control subjects were incubated under basal conditions or with the addition of LA at $100 \mathrm{ng} / \mathrm{ml}$; the conditioned media were collected and assayed for IL- $1 \beta$ using commercial ELISA kits. $* P<0.05$ versus basal; $* * P<0.03$ versus basal.

In addition, we found no differences in VEGF release between endometrial cell cultures from endometriosis patients and controls (Table I).

\section{Discussion}

Endometriotic implants are known to regress following the induction of hypo-estrogenism. To date, the basis of most of the therapeutic agents for endometriosis, including GnRH agonists and $\mathrm{GnRH}$ antagonists, is to achieve regression of the endometriotic implants through the induction of systemic hypo-estrogenism (Rice, 2002). The local anti-proliferative effects of GnRH agonists seems to be not only through suppression of gonadal steroids, but also through a direct effect on cell growth. There is convincing in-vitro evidence showing that GnRH agonists can directly inhibit the proliferation of endometrium as well as several types of cancer cells (Emons et al., 1998; Meresman et al., 2003).

In this study, epithelial cell cultures of human endometrium were used as a model to evaluate apoptosis, as well as IL-1 $1 \beta$ and VEGF release, in response to the addition of a GnRH agonist, a GnRH antagonist or both to the cultures. Although the cells employed in this investigation were not derived from endometriotic implants, and therefore their in-vitro response may not be identical, the rationale for the use of endometrial cells in shortterm culture as a model for endometriotic implants is scientifically acceptable and has been documented in the literature (Surrey and Halme, 1990; Meresman et al., 2003).

In our study, we found that LA increased the apoptotic rate in eutopic endometrial cells from controls and endometriosis patients. This finding is in agreement with the report by Andreu et al. (1998), showing that incubation with a GnRH agonist stimulated apoptosis in rat granulosa cells, as well as with a recent study reporting that a $\mathrm{GnRH}$ agonist triggered apoptosis in a single suspension of stromal and glandular epithelial endometrial cells from patients with endometriosis (Imai et al., 2000). These findings, as well as the data contained in the present study, seems to confirm that GnRH agonists may be effective in reducing the growth of endometrial cells not only

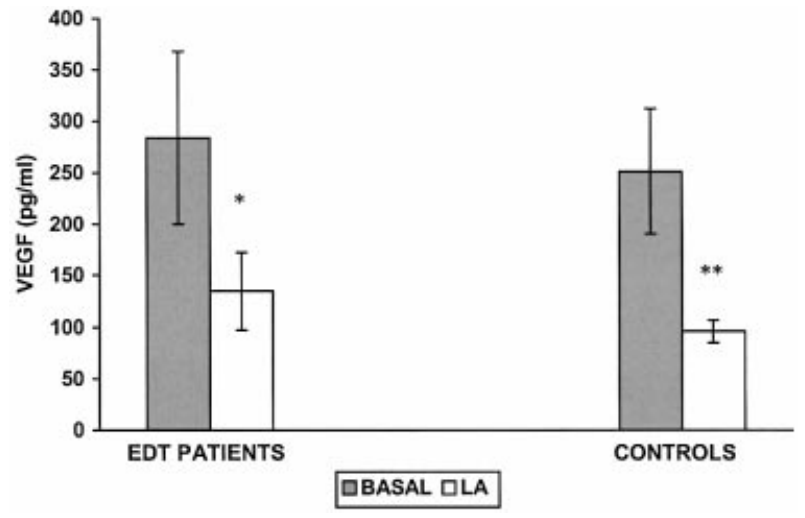

Figure 3. Effects of LA on VEGF release by epithelial endometrial cell cultures. Epithelial cell cultures from patients with endometriosis (EDT) and control subjects were incubated under basal conditions or with the addition of LA at $100 \mathrm{ng} / \mathrm{ml}$; the conditioned media were collected and assayed for VEGF using commercial ELISA kits. $* P<0.04$ versus basal; $* * P<0.03$ versus basal.

through an indirect effect (via causing hypoestrogenism), but also through a direct effect on the endometrial tissue.

VEGF is an important angiogenic factor and IL-1 $\beta$ is an important pleiotrophic factor that appear to be involved in the establishment and progression of endometriosis (Lebovic et al., 2000). The human endometrium and endometriotic tissue were found to express significant levels of VEGF and IL-1 $\beta$ (Donnez et al., 1998; Bergqvist et al., 2001). In addition, their concentrations were found to be elevated in peritoneal fluid from patients with endometriosis (Mori et al, 1992; McLaren et al., 1996) and it was suggested that IL-1 $\beta$ could induce VEGF expression in endometriotic cells (Lebovic et al., 2000).

In the present study, we showed for the first time that VEGF and IL- $1 \beta$ content in the conditioned media from endometrial cell cultures exposed to a GnRH agonist were significantly lower than the concentrations encountered under basal conditions in the same cultures. Our results are in agreement with those of Kupker et al. (1998) suggesting that after GnRH agonist therapy, endometriosis patients showed a significant drop in the mean concentrations of VEGF in the peritoneal fluid. VEGF expression was found to be elevated in the endometrium from patients with endometriosis and in the endometriotic tissue itself (Donnez et al., 1998; McLaren, 2000). We propose that GnRH agonist therapy seems to regulate the angiogenic activity of the endometriotic lesions by modulating the secretion of angiogenic factors.

The same was true for IL-1 $\beta$; Taketani et al. (1992) found that the levels of this cytokine was significantly higher in the peritoneal fluid from women with active endometriosis, compared with patients without the disease, but that the levels were extremely low in women with endometriosis who had undergone medical treatment with either danazol or buserelin. Based on these data, and on our own results, the possibility remains that $\mathrm{GnRH}$ agonists modulate the production of specific cytokines, and in turn regulate the growth of the endometriotic tissue.

In our study, the GnRH antagonist ANT by itself did not produce any significant effects on epithelial endometrial cells in culture, but it was able to prevent the enhanced effect of the 
GnRH agonist on programmed cell death, and reversed the inhibition by LA of VEGF and IL- $1 \beta$ release. These findings combined strongly suggest that the direct effects of GnRH agonists on endometrial cells in vitro are probably mediated by homologous GnRH receptors.

We did not find significant differences in the rate of apoptosis or in VEGF and IL-1 $\beta$ release between endometrial cell cultures from endometriosis patients and controls; this finding of a similar degree of apoptosis in these two different groups of patients is in contrast to the results observed in whole endometrial sections in our previous study (Meresman et al., 2000). We could speculate that after 4 days in culture of the glandular fraction, the epithelial endometrial cells altered their initial conditions, and therefore we could not detect maintenance of their apoptotic characteristics in comparison with when the entire tissue was used.

In conclusion, GnRH agonists appear to have a direct local effect on endometrial cells in culture; this effect is manifested by the enhancement in the percentage of apoptotic cells as well as by the significant inhibition observed in the release of promitogenic cytokines such as IL-1 $\beta$ and VEGF. Furthermore, we were unable to observe a significant direct effect of a GnRH antagonist on any of the parameters studied, on the same tissue cultures, although it was able to reverse the effects caused by the GnRH agonist.

\section{Acknowledgements}

This study was supported by grants from ANPCYT (Agencia Nacional de Promoción Científica y Técnica) and Roemmers Foundation, Buenos Aires, Argentina.

\section{References}

Abrams, J.M., White, K., Fessler, L.I. and Steller, H. (1993) Programmed cell death during Drosophila embryogenesis. Development, 117, 29-43.

American Society for Reproductive Medicine. (1997) Revised American Society for Reproductive Medicine classification of endometriosis: 1996. Fertil. Steril., 67, 817-821.

Andreu, C., Parborell, F., Vanzulli, S., Chemes, H. and Tesone, M. (1998) Regulation of follicular luteinization by a gonadotrophin-releasing hormone agonist: relationship between steroidogenesis and apoptosis. Mol. Reprod. Dev., 51, 287-294.

Bachelder, R.E., Crago, A., Chung, J., Wendt, M.A., Shaw, L.M., Robinson, G. and Mercurio, A.M. (2001) Vascular endothelial growth factor is an autocrine survival factor for neuropilin-expressing breast carcinoma cells. Cancer Res., 61, 5736-5740.

Bergqvist, A., Bruse, C., Carlberg, M. and Carlstrom, K. (2001) Interleukin $1 \beta$, interleukin- 6 , and tumor necrosis factor- $\alpha$ in endometriotic tissue and in endometrium. Fertil. Steril., 75, 489-495.

Bongso, A., Gajra, B., Lian, N.P., Wong, P.C., Soon-Chye, N. and Ratnam, S. (1988) Establishment of human endometrial cell cultures. Hum. Reprod., 3, 705-713.

Borroni, R., Di Blasio, A.M., Gaffuri, B., Santorsola, R., Busacca, M., Vigano, P. and Vignali, M. (2000) Expression of GnRH receptor gene in human ectopic endometrial cells and inhibition of their proliferation by leuprolide acetate. Mol. Cell. Endocrinol., 159, 37-43

Dias, S., Choy, M., Alitalo, K. and Rafii, S. (2002) Vascular endothelial growth factor (VEGF)-C signaling through FLT-4 (VEGFR-3) mediates leukemic cell proliferation, survival, and resistance to chemotherapy. Blood, 99, 2179-2184.

Dinarello, C.A. (1997) Interleukin-1. Cytokine Growth Factor Rev., 8, 253-265.

Donnez, J., Smoes, P., Gillerot, S., Casanas-Roux, F. and Nisolle, M. (1998) Vascular endothelial growth factor (VEGF) in endometriosis. Hum. Reprod., 13, 1686-1690.

Emons, G., Muller, V., Ortmann, O. and Schulz, K.D. (1998) Effects of
LHRH-analogues on mitogenic signal transduction in cancer cells. Steroid Biochem. Mol. Biol., 65, 199-206.

Harmey, J.H. and Bouchier-Hayes, D. (2002) Vascular endothelial growth factor (VEGF), a survival factor for tumour cells: implications for antiangiogenic therapy. Bioessays, 24, 280-283.

Harris, S.R., Schoeffner, D.J., Yoshiji, H. and Thorgeirsson, U.P. (2002) Tumor growth enhancing effects of vascular endothelial growth factor are associated with increased nitric oxide synthase activity and inhibition of apoptosis in human breast carcinoma xenografts. Cancer Lett., 179, 95-101.

Ho, H.N., Wu, M.Y. and Yang, Y.S. (1997) Peritoneal cellular immunity and endometriosis. Am. J. Reprod. Immunol., 38, 400-412.

Imai, A., Takagi, A. and Tamaya, T. (2000) Gonadotropin-releasing hormone analog repairs reduced endometrial cell apoptosis in endometriosis in vitro. Am. J. Obstet. Gynecol., 182, 1142-1146.

Jung, Y.D., Liu, W., Reinmuth, N., Ahmad, S.A., Fan, F, Gallick, G.E. and Ellis, L.M. (2001) Vascular endothelial growth factor is upregulated by interleukin-1 beta in human vascular smooth muscle cells via the P38 mitogen-activated protein kinase pathway. Angiogenesis, 4, 155-162.

Kupker, W., Schultze-Mosgau, A. and Diedrich, K. (1998) Paracrine changes in the peritoneal environment of women with endometriosis. Hum. Reprod. Update, 4, 719-723.

Lebovic, D.I., Bentzien, F., Chao, V.A., Garrett, E.N., Meng, Y.G. and Taylor, R.N. (2000) Induction of an angiogenic phenotype in endometriotic stromal cell cultures by interleukin-1ß. Mol. Hum. Reprod., 6, 269-275.

Liu, W., Ahmad, S.A., Reinmuth, N., Shaheen, R.M., Jung, Y.D., Fan, F. and Ellis, L.M. (2000) Endothelial cell survival and apoptosis in the tumor vasculature. Apoptosis, 5, 323-328

Markstrom, E., Svensson, E.Ch., Shao, R., Svanberg, B. and Billig, H. (2002) Survival factors regulating ovarian apoptosis-dependence on follicle differentiation. Reproduction, 123, 23-30.

McLaren, J. (2000) Vascular endothelial growth factor and endometriotic angiogenesis. Hum. Reprod. Update, 6, 45-55.

McLaren, J., Prentice, A., Charnock-Jones, D.S., Millican, S.A., Muller, K.H., Sharkey, A.M. and Smith, S.K. (1996) Vascular endothelial growth factor is produced by peritoneal fluid macrophages in endometriosis and is regulated by ovarian steroids. J. Clin. Invest., 98, 482-489.

Meresman, G.F., Vighi. S., Buquet, R.A., Contreras-Ortiz, O., Tesone, M. and Rumi, L.S. (2000) Apoptosis and expression of Bcl-2 and Bax in eutopic endometrium from women with endometriosis. Fertil. Steril., 74, 760-766.

Meresman, G.F Auge, L., Barañao, R.I., Lombardi, E., Tesone, M. and Sueldo, C. (2002) Oral contraceptives treatment suppresses proliferation and enhances apoptosis of eutopic endometrial tissue from patients with endometriosis. Fertil. Steril., 77, 1141-1147.

Meresman, G.F., Buquet, R.A., Bilotas, M., Barañao, R.I., Sueldo, C. and Tesone, M. (2003) Gonadotropin-releasing hormone agonist (GnRH-a) induces apoptosis and reduces cell proliferation in eutopic endometrial cultures from women with endometriosis. Fertil. Steril., 80(Suppl. 2), in press.

Mori, H., Sawairi, M., Nakagawa, M., Itoh, N., Wada, K. and Tamaya, T. (1992) Expression of interleukin-1 (IL-1) beta messenger ribonucleic acid (mRNA) and IL-1 receptor antagonist mRNA in peritoneal macrophages from patients with endometriosis. Fertil. Steril., 57, 535-542.

Neufeld, G., Cohen, T., Gengrinovitch, S. and Poltorak, Z. (1999) Vascular endothelial growth factor (VEGF) and its receptors. FASEB J., 13, 9-22.

Plosker, G.L. and Brogden, R.N. (1994) Leuprorelin: a review of its pharmacology and therapeutic use in prostatic cancer, endometriosis and other sex hormone-related disorders. Drugs, 48, 930-967.

Rice, V.M. (2002) Conventional medical therapies for endometriosis. Ann. NY Acad. Sci., 955, 343-352.

Sidell, N., Han, S.W. and Parthasarathy, S. (2002) Regulation and modulation of abnormal immune responses in endometriosis. Ann. NY Acad. Sci., 955, $159-173$.

Simonart,T. and van Vooren, J.P. (2002) Interleukin-1 $\beta$ increases the bcl-2/ bax ratio in Kaposi's sarcoma cells. Cytokine, 19, 259-266.

Smith, S.K. (2001) Regulation of angiogenesis in the endometrium. Trends Endocrinol. Metab., 12, 147-151.

Surrey, E.S. and Halme, J. (1990) Effect of peritoneal fluid from endometriosis patients on endometrial stromal cell proliferation in vitro. Obstet. Gynecol., 76, 792-797.

Taketani, Y., Kuo, T.M. and Mizuno, M. (1992) Comparison of cytokine levels and embryo toxicity in peritoneal fluid in infertile women with untreated or treated endometriosis. Am. J. Obstet. Gynecol., 167, 265-270.

Submitted on February 17, 2003; accepted on May 13, 2003 